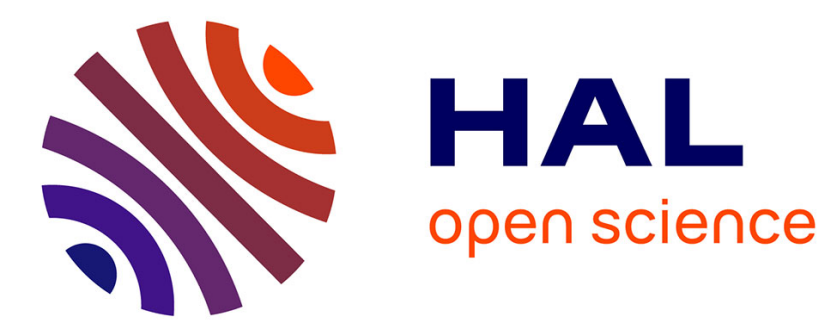

\title{
Oxygen Transport Impedance in a Polymer Electrolyte Membrane Fuel Cell Equivalent Electrical Circuit
}

W Aït-Idir, S Touhami, M Daoudi, Jérôme Dillet, Julia Mainka, Olivier Lottin

\section{To cite this version:}

W Aït-Idir, S Touhami, M Daoudi, Jérôme Dillet, Julia Mainka, et al.. Oxygen Transport Impedance in a Polymer Electrolyte Membrane Fuel Cell Equivalent Electrical Circuit. 2021 International Workshop on Impedance Spectroscopy (IWIS), Sep 2021, Chemnitz, Germany. hal-03333680

\section{HAL Id: hal-03333680 \\ https://hal.science/hal-03333680}

Submitted on 3 Sep 2021

HAL is a multi-disciplinary open access archive for the deposit and dissemination of scientific research documents, whether they are published or not. The documents may come from teaching and research institutions in France or abroad, or from public or private research centers.
L'archive ouverte pluridisciplinaire HAL, est destinée au dépôt et à la diffusion de documents scientifiques de niveau recherche, publiés ou non, émanant des établissements d'enseignement et de recherche français ou étrangers, des laboratoires publics ou privés. 


\title{
Oxygen Transport Impedance in a Polymer Electrolyte Membrane Fuel Cell Equivalent Electrical Circuit
}

\author{
W. Aït-Idir, S. Touhami, M. Daoudi, J. Dillet, J. Mainka*, O. Lottin \\ Université de Lorraine, CNRS, LEMTA, F-54000 Nancy, France \\ * julia.mainka@univ-lorraine.fr
}

\begin{abstract}
One common way to interpret the data of Electrochemical Impedance Spectroscopy (EIS) with Polymer Exchange Membrane Fuel Cells (PEMFC) consists in using an Equivalent Electrical Circuit (EEC). There are however various issues in EEC modeling, among which the location and expression of the oxygen transport impedance. In this work, we compare the results obtained using a Randles circuit with those of an EEC where the oxygen diffusion impedance is connected in series with the circuit of the Cathode Catalyst Layer (CCL). In the Randles circuit, the oxygen transport impedance is in series with the charge transfer resistance of the Oxygen Reduction Reaction (ORR), implying that the CCL (pores and/or ionomer) is governing oxygen diffusion. In the other case, the oxygen diffusion impedance is outside of the CCL circuit, which implicates that the Gas Diffusion Layer (GDL) governs oxygen diffusion. In addition, two expressions of the GDL oxygen diffusion impedance were tested: the usual finite Warburg impedance and an alternative expression derived by Kulikovsky that considers the impact of the double-layer capacity on oxygen concentration at the CCL/GDL interface. The parameters obtained with these EEC are used to estimate the main characteristic diffusion length, for various cells and operating conditions. The same trend was observed in all cases: the values of the characteristic diffusion length are found to be of the order of the GDL thickness.
\end{abstract}

Keywords - PEM Fuel Cell, Electrochemical Impedance Spectroscopy, Oxygen Transport Impedance, Electrical Equivalent Circuit Modeling

\section{I- INTRODUCTION}

In this work, we focus on the interpretation of impedance spectra of PEMFC, i.e. assemblies of a proton exchange membrane, Anode and Cathode Catalyst Layers (ACL and CCL), and two Gas Diffusion Layers (GDL). The most widely used Equivalent Electrical Circuit (EEC) to describe such electrochemical converters is the Randles circuit. Applied to PEMFC, this EEC is an electrical schematization of the membrane, the CCL, as well as -possibly- the cathode GDL through a finite-length Warburg impedance accounting for oxygen transport limitations.

Despite of the wide use of the Randles EEC, its physical relevance remains to be discussed on several points. Regarding oxygen transport limitations, Touhami et al. [1] and Bultel et al. [2] showed for instance that they are located mainly in the GDL [3] when the FC is fed with air. However, some other works point the ionomer layer covering the reaction sites in the CCL as limiting for oxygen transport, especially for electrodes with low Pt loadings -because of high local mass fluxes- and/or when the fuel cell is operating at low relative- humidity [4] [5] [6]. In addition to this obvious absence of consensus, it is worth mentioning that the low frequency impedance is also strongly impacted by oxygen concentration oscillations induced by the measuring signal, and possibly by the water fluxes through the cell [7]. Since these points have been clarified, among others by Schneider [8] [9] et al., Maranzana et al. [10], and Mainka et al. [7], they will be considered as out of the scope of this work. However, it must be kept in mind that oxygen concentration oscillations must eventually be considered should the GDL be identified as limiting for oxygen transport.

Under the hypothesis of oxygen diffusion being limited by the GDL, Kulikovsky showed that the mass transport impedance should differ from the classical finite-length Warburg expression due to the high double-layer capacity $\mathrm{C}_{\mathrm{dl}}$ of the porous catalyst layer [11]. Kulikovsky derived an alternative expression which is a generalization of the GDL 
oxygen transport impedance: it tends toward the classical finite-length Warburg impedance $Z_{W}$ when the double-layer capacity $\mathrm{C}_{\mathrm{dl}}$ of the electrode tends toward zero. Note that in any case, the oxygen mass transport impedance through the catalyst layer is assumed negligible, which is consistent with the hypothesis of a thin (surface) electrode that governs the derivation of the Warburg impedance. However, this is not consistent with the usual structure of the Randles EEC, with $Z_{\mathrm{W}}$ connected in series with the charge transfer resistance $\mathrm{R}_{\mathrm{ct}}$, and both $\mathrm{R}_{\mathrm{ct}}$ and $\mathrm{Z}_{\mathrm{W}}$ being connected in parallel with the double-layer capacity $\mathrm{C}_{\mathrm{dl}}$ (Figure 1a): if the catalyst layer is indeed considered as a -simpleinterface, one would rather expect to have the Warburg impedance connected in series with both $\mathrm{R}_{\mathrm{ct}}$ and $\mathrm{C}_{\mathrm{dl}}$ (Figure 1a).

Recently, Cruz-Manzo and Greenwood [12] modelled oxygen diffusion through CCL and GDL using a Transmission Line Model (TLM), i.e. a generalization of the Randles circuit [13]. They proposed to include a diffusion impedance in each layer at the cathode side, and choose the finite-Warburg expression for the CCL and the Kulikovsky impedance for the GDL. They obtained similar values of the diffusion resistance when neglecting either the CCL or the GDL. These values correspond to the overall fuel cell diffusion impedance. Our approach was similar, and we discuss the position of the oxygen transport impedance in Randles-like (thin electrode model) circuits. The EEC were tested over a large range of operating conditions and with regular cathode materials, i.e. carbon-supported platinum with loadings varying between 0.1 and $0.4 \mathrm{mg} / \mathrm{cm}^{2}$. The impedance spectra were measured on three different cells and four different MEA: two commercial MEA and two homemade MEA. For the sake of simplicity, only one case will be fully described in this work. The impedance spectra were analyzed using two EEC:

- The classical Randles circuit (Figure 1a), for comparison purpose.

- And a modified Randles circuit (Figure 1b) with the oxygen diffusion impedance connected in series to the catalyst layer, i.e. with an oxygen transport impedance located outside the catalyst layer. This is consistent with the assumption that the main limitation to oxygen transport comes from the GDL, and with the hypotheses governing the derivation of both the Warburg and Kulikovsky impedances in a passive media.

We then compared the results obtained with both EEC. Note that the anode was also considered in the impedance models to get a better fit between theoretical and experimental data. This choice was consistent with one of our previous work where we had observed a degradation of the anode [14]. However, in the absence of anode degradation, similar or perhaps better fits may have been obtained using a TLM model for the CCL, i.e. without considering the anode. A more detailed discussion on this point will be presented in a future work.

\section{II- EXPERIMENTAL SETUP}

Although the data used in this work were measured over a wide range of operating conditions and using three very different cells, we describe here only those obtained with one of them: a $30 \mathrm{~cm}^{2}(300 \mathrm{~mm} \times 10 \mathrm{~mm})$ cell with identical flow fields on the anode and cathode sides, i.e. 5 parallel straight channels. The channel width and depth were equal to $1 \mathrm{~mm}$ and $0.7 \mathrm{~mm}$, respectively. In addition to its simplified geometry, another particularity of this cell lies in the current collection, which is done independently on 20 electrically isolated segments along the channel length: this allows the measurement of the local impedance on each of these segments. A more complete description of this instrumented and segmented cell can be found in our previous work, see for instance [14]. Impedance data were measured in galvanostatic mode, -mostly at $0.5 \mathrm{~A} . \mathrm{cm}^{-2}$ - with a perturbation amplitude of $10 \%$ for frequencies ranging from $10 \mathrm{mHz}$ to $10 \mathrm{kHz}$, and with 10 points per decade.

Tailored MEA made by an external supplier with Nafion ${ }^{\circledR}$ XL membranes were used. The Pt loadings were 0.1 $\mathrm{mg}_{\mathrm{Pt}} . \mathrm{cm}^{-2}$ for the anode and $0.3 \mathrm{mg}_{\mathrm{Pt} . \mathrm{cm}^{-2}}$ for the cathode. The gas diffusion layers were $235 \mu \mathrm{m}$ thick Sigracet $28 \mathrm{BC}$, compressed to $175 \mu \mathrm{m}$ using PTFE gaskets to control their thickness. The fuel cell temperature was maintained at $80^{\circ} \mathrm{C}$. The relative humidities (RH) of air and hydrogen supplied to the cell were $70 \%$ and $50 \%$, respectively. The air stoichiometry was set to 2 , while for hydrogen it was set to 1.5 .

\section{III-ELECTRICAL EQUIVALENT CIRCUITS}

Two different EEC were used to analyze the impedance shown in Fig. 1: a classical and a modified Randles EEC standing for the cathode catalyst layer, the other electrical resistances being accounted for through a high frequency resistance $R_{h f}$. $R_{h f}$ is usually associated to the ionic transport resistance of the membrane, although in practice it also 
includes the contribution of other components such as the GDL and flow field plates, as well as interfaces between them. The Oxygen Reduction Reaction (ORR) in the CCL is modeled through a parallel connection of a charge transfer resistance $R_{c t}$ accounting for the reaction kinetics and a double-layer capacitance $C_{d l}$ representing the capacity of the porous electrode to store charges in the Electrical Double-Layer (EDL) at the carbon-electrolyte interface. The anode was modelled through a parallel connection of a double-layer capacitance and a charge transfer resistance (hydrogen transport limitations being generally negligible), added in series with the cathode and membrane EEC [14] [13].

(a)

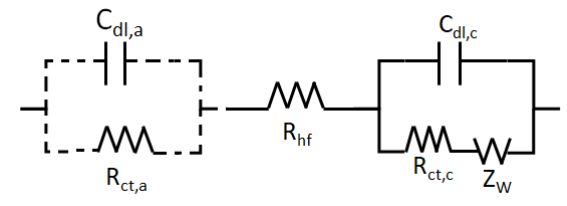

(b)

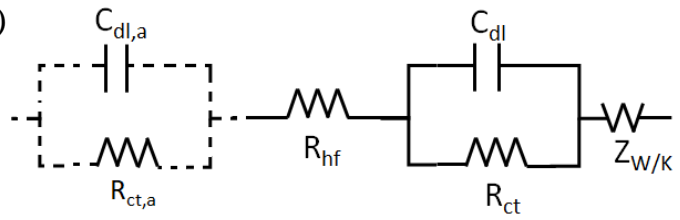

Figure 1 EECs used to fit the experimental impedance spectra, usual (a) and modified (b) Randles circuits.

The difference between both EEC lies in the position of the oxygen transport impedance $Z_{\mathrm{W}}$ or $Z_{\mathrm{K}}$ : in the classical Randles configuration $Z_{W}$ is connected in series with the charge transfer resistance (Fig. 1a). Implicitly, this configuration implies that the main limitations to oxygen transport are located in the CCL (i.e. in the pores or in the ionomer layer covering the reaction sites) although in practice, the GDL may also contribute significantly. In the modified Randles EEC, the oxygen diffusion impedance is connected in series with the CCL impedance (Fig. 1b). Although rarely used, this last configuration is consistent with the hypothesis that the GDL is the most limiting component for oxygen transport [1].

The impedance of the oxygen transport through a (passive) porous media is usually accounted for through a finitelength Warburg element $Z_{\mathrm{W}}$ [15]. This impedance is derived from Fick's diffusion equations. It is thus based on the assumptions of one-dimensional transport of oxygen and water by binary diffusion only, with as boundary conditions a surface reaction at the $\mathrm{CCL} /$ membrane interface (Neumann or second-type boundary condition, the oxygen flux being governed by the current density) and a constant oxygen concentration (Dirichlet or first-type boundary condition) at the CCL/air channel or GDL/air channel interface. The hypothesis of a constant oxygen concentration is reasonable for relatively high stoichiometry ratios [13], i.e. for relatively low currents. The Warburg impedance writes as [15]:

$$
Z_{W}=R_{d} \frac{\tanh \sqrt{i \omega \tau_{d}}}{\sqrt{i \omega \tau_{d}}}
$$

where $R_{d}$ corresponds to the diffusion resistance $\left(\Omega . \mathrm{cm}^{2}\right), \omega=2 \pi \nu$ the angular frequency $(\mathrm{rad}), \tau_{\mathrm{d}}$ the characteristic diffusion time (s).

However, Kulikovsky showed that the oxygen transport impedance of the GDL differs from the Warburg impedance due to the high double-layer capacitance of the porous CCL, that actually impacts the faradic current density and the oxygen flux. He derived a modified expression of the oxygen transport impedance as a function of the impedance parameters of the ORR which writes as [11]:

$$
\mathrm{Z}_{\mathrm{K}}=\frac{\mathrm{Z}_{\mathrm{W}}}{1+\mathrm{i} \omega \mathrm{C}_{\mathrm{dl}} \mathrm{R}_{\mathrm{ct}}}
$$

with $\mathrm{C}_{\mathrm{dl}}$ the double-layer capacitance $\left(\mathrm{F} / \mathrm{cm}^{2}\right)$ and $\mathrm{R}_{\mathrm{ct}}$ the charge transfer resistance $\left(\Omega . \mathrm{cm}^{2}\right)$. This expression can be used to model the impedance of the cathode gas diffusion layer, and it tends toward the Warburg impedance when $\mathrm{C}_{\mathrm{dl}}$ tends toward zero.

In the next section, we compare the ability of a classical Randles EEC using a Warburg oxygen transport impedance (Figure 1a) and that of a modified EEC -with the oxygen diffusion impedance connected in series with the CCL impedance (Figure 1b)- to fit various experimental impedance spectra. The mathematical expression of the usual Randles EEC is recalled below [1] [14] [16]:

$$
\mathrm{Z}_{\mathrm{EEC}}=\mathrm{R}_{\mathrm{hf}}+\left(\frac{1}{\mathrm{R}_{\mathrm{ct}}+\mathrm{Z}_{\mathrm{W}}}+\mathrm{i} \omega \mathrm{C}_{\mathrm{dl}}\right)^{-1}
$$


And the mathematical expression of the modified EEC (Figure 1b) is given by:

$$
\mathrm{Z}_{\mathrm{EEC}}=\mathrm{R}_{\mathrm{hf}}+\left(\frac{1}{\mathrm{R}_{\mathrm{ct}}}+\mathrm{i} \omega \mathrm{C}_{\mathrm{dl}}\right)^{-1}+\mathrm{Z}_{\mathrm{W} / \mathrm{K}}
$$

Also, for comparison purpose, we use either the classical Warburg oxygen transport impedance $Z_{\mathrm{W}}$ in (4) or the modified expression proposed by Kulikovsky $Z_{K}(2)$. The Kulikovsky expression was not used with the conventional Randles circuit because of the various shortcomings of this EEC mentioned earlier.

\section{IV-RESULTS}

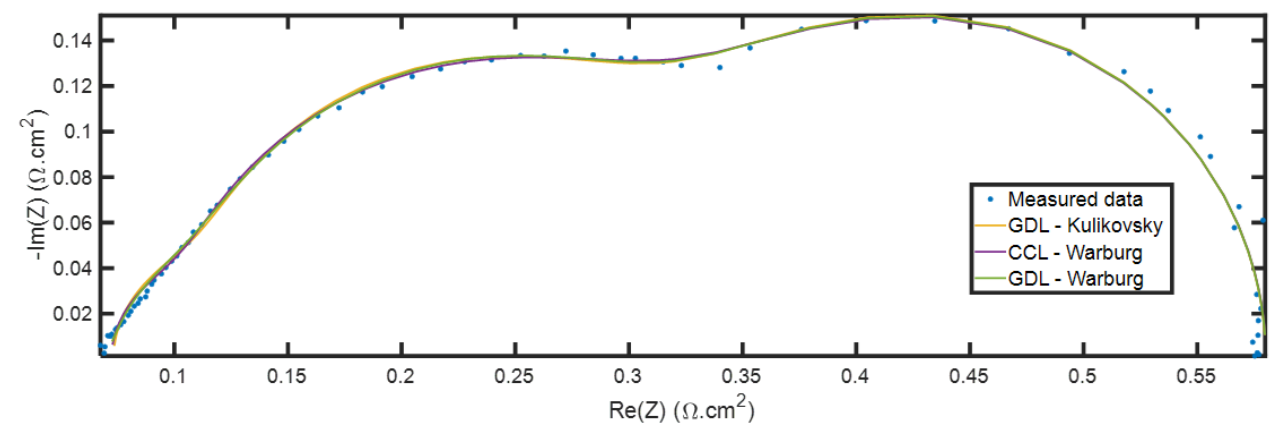

Figure 2. Experimental Nyquist diagram measured in operando at $0.5 \mathrm{~A} . \mathrm{cm}^{-2}$ in the operation conditions described in section II and fitting curves obtained with the EEC depicted in Fig 1.

TABLE I. ESTIMATED PARAMETERS OBTAINED FROM THE EXPERIMENTAL DATA IN FIG 2 USING THE EEC IN FIG 1. COMPARISON BETWEEN THE DIFFUSION IMPEDANCE POSITION (CCL OR GDL) OF WARBURG AND THE COMPARISON BETWEEN WARBURG \& KULIKOVSKY IMPEDANCES.

\begin{tabular}{|c|c|c|c|c|c|c|c|}
\hline Model & $\begin{array}{c}\mathbf{R}_{\mathrm{hf}} \\
{\left[\Omega \cdot \mathbf{c m}^{2}\right]}\end{array}$ & $\begin{array}{c}\mathbf{R}_{\mathrm{ct}} \\
{\left[\Omega \cdot \mathbf{c m}^{2}\right]}\end{array}$ & $\begin{array}{c}\mathbf{C}_{\mathrm{dl}} \\
{\left[\mathbf{m F} . \mathbf{c m}^{-2}\right]}\end{array}$ & $\begin{array}{c}\mathbf{R}_{\mathrm{d}} \\
{\left[\Omega \cdot \mathbf{c m}^{2}\right]}\end{array}$ & $\begin{array}{c}\mathbf{T} \\
{[\mathbf{s}]}\end{array}$ & $\begin{array}{c}\mathbf{R}_{\mathrm{ct}} \text { anode } \\
{\left[\mathbf{\Omega} . \mathrm{cm}^{2}\right]}\end{array}$ & $\begin{array}{c}\mathbf{C}_{\mathrm{dll}} \text { anode } \\
{\left[\mathbf{F} . \mathbf{c m}^{-2}\right]}\end{array}$ \\
\hline Warburg CCL & 0.072 & 0.212 & 19.5 & 0.262 & 0.128 & 0.033 & 0.011 \\
\hline Warburg GDL & 0.068 & 0.169 & 31.2 & 0.320 & 0.137 & 0.024 & 0.020 \\
\hline Kulikovsky GDL & 0.073 & 0.168 & 25.4 & 0.296 & 0.137 & 0.042 & 0.011 \\
\hline
\end{tabular}

Regarding the impact of the layer governing oxygen transport (CCL or GDL), the experimental data were equally well fitted using the finite-Warburg impedance, with similar values of the residuals. However, the location of the diffusion impedance impacts visibly the parameters associated with mass transfer $\left(+8 \%\right.$ for $\tau$ and $+22 \%$ for $\mathrm{R}_{\mathrm{d}}$, with reference to the values obtained with the Warburg in the CCL) and much more significantly those associated with the ORR kinetics: the charge transfer resistance dropped by $21 \%$ and the double-layer capacitance was almost $60 \%$ higher. Only the high-frequency resistance remains almost independent from the location of oxygen diffusion impedance, at least in this thin electrode EEC approach. Independently of the expression of the oxygen diffusion impedance (i.e. Warburg or Kulikovsky) considering that the GDL governs oxygen transport increases the contribution of the diffusion to the cell impedance ( $\tau$ and $R_{d}$ ), while decreasing that of the charge transfer resistance. In addition, it can be seen that the choice of the diffusion impedance has only a slight impact on the other parameters.

To go one step further in the identification of the layer governing oxygen diffusion, the characteristic diffusion length was estimated using the following expression [1]:

$$
\delta=\left(1+\frac{R_{c t}}{R_{d}}\right) \times \frac{j_{\text {cell }} \tau}{4 F\left\langle C_{O_{2}}(O)\right\rangle_{t}}
$$

The above equation is obtained using $R_{c t}=b_{c} /\left\langle j_{c e l l}\right\rangle_{t} ; R_{d}=b_{c} \delta / 4 F D_{\text {eff }}\left\langle C_{O_{2}}(0)\right\rangle_{t}$ and $\tau_{d}=\delta^{2} / D_{\text {eff }}$ [14], with $\mathrm{j}_{\text {cell }}$ the current density $\left(0.5 \mathrm{~A} / \mathrm{cm}^{2}\right.$ in this case $), F$ the Faraday constant $\left(96485 \mathrm{C} \mathrm{mol}^{-1}\right)$ and $\left\langle C_{O_{2}}(O)\right\rangle_{t}$ the oxygen concentration at the GDL/channel interface, assessed by solving Fick's equation in steady- state [17]:

$$
\left\langle C_{O_{2}}(O)\right\rangle_{t}=C_{O_{2}}^{*}-\frac{\left\langle j_{\text {cell }}\right\rangle_{t} \delta}{4 F D_{\text {eff }}}
$$


with $C_{O_{2}}^{*}$ the oxygen concentration in the gas channel supposed constant, and $D_{\text {eff }}$ the effective oxygen diffusion coefficient, given by $D_{e f f}=\delta^{2} / \tau_{d}$ [1]. The porosities of the GDL and the CCL were then determined with $\varepsilon_{C C L}=$ $\left(\frac{D_{\text {eff }}}{6.910^{-6}}\right)^{(2 / 3)}$ and $\varepsilon_{G D L}=\left(\frac{D_{\text {eff }}}{3.210^{-5}}\right)^{0.5}[18]$.

The values obtained using the impedance data of Table I are given in Table II: the characteristic length is much closer to a GDL than a CCL thickness, independently of the location and expression of the oxygen diffusion impedance.

TABLE II. CHARACTERISTIC VALUES OBTAINED WITH THE IMPEDANCE PARAMETERS OF TABLE I.
\begin{tabular}{|c|c|c|c|}
\hline Model & Warburg CCL & Warburg GDL & Kulikovsky GDL \\
\hline$\delta[\mu \mathrm{m}]$ & 308 & 359 & 302 \\
\hline Deff $\left[\mathrm{m}^{2} / \mathrm{s}\right] \mathbf{~ 1 0}^{-6}$ & 1.35 & 1.92 & 1.25 \\
\hline Porosity [-] & 0.20 & 0.32 & 0.20 \\
\hline
\end{tabular}

\section{V- CONCLUSION}

The characteristic diffusion length of oxygen transport in PEMFC was determined from experimental impedance data considering two EEC differing in the locations (CCL and GDL) and expressions (finite-Warburg and Kulikovsky) of the oxygen transport impedance. This analysis was repeated on three different cells, various current densities and gas stoichiometries. The oxygen diffusion was also identified locally on each segment of the segmented cell. Although they cannot be detailed in this work, the results always stayed consistent: it is most likely the GDL that governs oxygen diffusion in usual operating conditions of PEMFC.

\section{VI-REFERENCES}

[1] S. Touhami, J. Mainka, J. Dillet, S. Ait Hammou Taleb and O. Lottin, J. Electrochem. Soc., vol. 166, pp. F1209F1217, 2019.

[2] Y. Bultel, K. Wiezell, F. Jaouen, P. Ozil and G. Lindbergh, Electrochimica Acta, vol. 51, pp. 474-488, 2005.

[3] J. Ihonen, M. Mikkola and G. Lindbergh, J. Electrochem. Soc., vol. 151, pp. A1152-A1161, 2004.

[4] J. P. Owejan, J. E. Owejan and W. Gu, J. Electrochem. Soc., vol. 160, pp. F824-F833, 2013.

[5] N. Nonoyama, S. Okazaki, A. Z. Weber, Y. Ikogi and T. Yoshida, J. Electrochem. Soc., vol. 158, pp. B416B423, 2011.

[6] A. Kulikovsky, Electrochemistry Communications, vol. 103, pp. 61-65, 2019.

[7] J. Mainka, G. Maranzana, A. Thomas, J. Dillet, S. Didierjean and O. Lottin, Fuel Cells, vol. 12, no. 5, pp. 848861, 2012.

[8] I.A. Schneider, S.A. Freunberger, D. Kramer, A. Wokaun and G.G. Scherer, J. Electrochem. Soc., vol. 154, pp. B383-B388, 2007.

[9] I.A. Schneider, D. Kramer, A. Wokaun and G.G. Scherer, J. Electrochem. Soc., vol. 154, pp. B770-B782, 2007.

[10] G. Maranzana, J. Mainka, O. Lottin, J. Dillet, A. Lamibrac, A. Thomas and S. Didierjean, Electrochimica Acta , vol. 83, pp. 13-27, 2012.

[11] A. Kulikovsky, Electrochemistry Communications, vol. 84, pp. 28-31, 2017.

[12] S. Cruz-Manzo and P. Greenwood, J. Electrochem. Soc., vol. 892, 2021.

[13] J. Mainka, G. Maranzana, J. Dillet, S. Didierjean and O. Lottin, Journal of Power Sources, vol. 253, pp. 381391, 2014.

[14] S. Touhami, L. Dubau, J. Mainka, J. Dillet, M. Chatenet and O. Lottin, Journal of Power Sources, vol. 481, 2021.

[15] E. Warburg, Ann. Physik und Chemie, vol. 3, pp. 493-499, 1899.

[16] J. E. B. Randles, Discussions of the Faraday Society, vol. 1, pp. 11-19, 1947.

[17] J. Mainka, G. Maranzana, J. Dillet, S. Didierjean and O. Lottin, J. Electrochem. Soc., vol. 157, pp. B1561-B1568, 2010.

[18] R.B. Bird, W.E. Stewart and E.N. Lightfood, Transport Phenomena, 2002. 